\title{
Nature of Centennial Global Climate Change from Observational Records
}

\author{
Mohammed Anwer \\ Department of Physical Sciences, Independent University, Bangladesh, Dhaka, Bangladesh \\ Email: manwer55@hotmail.com
}

Received 8 April 2015; accepted 21 August 2015; published 24 August 2015

Copyright (C) 2015 by author and Scientific Research Publishing Inc.

This work is licensed under the Creative Commons Attribution International License (CC BY). http://creativecommons.org/licenses/by/4.0/

(c) (i) Open Access

\section{Abstract}

In order to provide a better benchmark for climate simulation programs, climate data at Global Historical Climatology Network (GHCN) and Global Summary of the Day (GSOD) archived by the National Climate Data Center (NCDC) are used to ascertain the nature of climate change over the last century. After data validation, about 6000 stations are considered globally to determine the change in mean temperature, and about $\mathbf{5 0 0 0}$ stations to determine that change in maximum and minimum temperatures. Global nature of temperature and its change are presented separately for January and July. Both maximum and minimum daily temperatures are used in the analysis. Trend of global change in annual precipitation is also reported here. Least square linear regression is used to ascertain the nature of these changes. Global nature of temperatures in both January and July show bimodal distributions, with the geographical region between the tropics in one mode and the region outside the tropic in another mode. The individual distributions of temperatures of both these regions show separate and similar histograms. Results indicate that over the last century, temperature in January increased more than that during July. Furthermore the minimum temperature in each case increased more than the maximum temperature. Ten separate estimates of temperature change are obtained from the data presented here using different methods. Considering all these estimates, the mean rise in temperature during January was $2.19^{\circ} \mathrm{C}$, and during July was $1.72^{\circ} \mathrm{C}$. The geographical nature of the rise in temperature shows that though it rises in most locations, the temperature also reduces along eastern Asia, some parts of central Russia, along south-eastern Australia, and along the east coast of the United States. Predominant rise in temperature is mostly over Europe, and in the arctic. Change in precipitation shows that though there is significant reduction rainfall globally, rainfall increases along the equator, in areas around the Gulf of Mexico, along eastern Asia, along the western coast of India, and along the eastern coast of Australia.

\section{Keywords}

Climate Change, GHCN, GSOD, IPCC, NCPC, Temperature, Precipitation 


\section{Introduction}

Climate change and its impacts on society and humans have been extensively studied. Good et al. [1] and Gosling et al. [2] have provided an extensive review of large-scale change in the climate system, and its impact on different aspects of human lives. Among many other impacts, climate change is suspected for increased loss of ice sheet in Antarctica and Greenland [3] [4]; large drop in sea ice [5]-[7]; rise in sea level as a result of ice melting [8] [9]; acidification of oceans as a result of increased carbon dioxide in the atmosphere [8] [10] [11]; and reduced agriculture productivity and quality [12]-[14]. Bell et al. [15] have extensively discussed the health complications arising as a result of climate change in 50 US cities. Nevertheless, Mills [16] argues that there is a high degree of uncertainty associated with the effects of climate extremes on human health, as there is a high degree of uncertainty in the prediction of the change in climate variables.

These impacts of climate change are predicted considering a rise in temperature as a result of change in climate. Unfortunately, the estimate of the rise in the temperature is very wide. The prediction of the rise in temperature over the $21^{\text {st }}$ century by IPCC varies from $0.3^{\circ} \mathrm{C}$ to $6.4^{\circ} \mathrm{C}$ [8]. These variations arise from the fact that most of these predictions are built upon numerical simulation of the climate processes.

Significant progress has been made in climate modeling over the last several decades [17] [18]. Climate models are built on well-known physical principles involving interdependent systems like atmosphere, oceans, land, vegetations, clouds and human activities. These interdependent systems influence each other in a feedback process, which is highly nonlinear, and whose mechanism is not well understood [19] [20]. Bony et al. [21] elaborate upon our lack of understanding of the feedback system, and how this limitation of understanding results in different outcomes from different climate models. Caldiera et al. [22] have illustrated that these feedback processes work at different length and time scales, and vary with the time of the year. As a result, it has been difficult to construct a climate model that works at all length and time scales, and feedback forcing. Many largescale aspects of present-day climate are simulated quite well by different models. On the other hand, many small-scale processes that cannot be simulated explicitly in current climate models are important for the feedback effects that regulate the response of climate to changes in external forcing [23]. When running under similar scenarios of anthropogenic forcing, different climate models agree on many aspects of climate change but disagree on others. An investigation on the agreement and disagreement between different climate models has been a major focus in the IPCC assessments [24]-[26]. Recently, the US Department of Energy has started a Climate Model Intercomparison Project (CMIP) for the next evaluation report of IPCC [27]. Examples of multimodel analysis of surface temperature and precipitation are [28]-[35]. In addition, Hansen et al. [36] have also provided a multi-model comparison of surface air temperature with observational data from 1880 till 2003. These studies reveal that models perform only to the extent they are designed for. Furthermore, several investigations have demonstrated that comparison of predictions from different models is very poor [37]-[40]. The comparison between model predictions and observational data is even worse [18] [36]. Part of the reason for this poor comparison is a shortage of studies involving analysis of climate data.

In separate studies Hansen et al. [36] [41] [42] have reported on the analysis of actual climate data records, mainly for the United States. Their analysis of global data is more restrictive; using simulated data in many cases. They clearly emphasize on the discrepancies between simulation and observational data, and on the importance of a comprehensive analysis of global climate data to form a basis for validation of simulations programs. Therefore, this study has been undertaken with an objective to analyze observational records of climate data to provide a global nature of temperature and precipitation, and its change over the last century. It is expected that results presented here would provide a better understanding of the climate process, and hence would help to construct more robust climate models.

\section{Objectives of the Study}

This study will try to present the global trend of change in climate over the last century. This will be done by using the observational records at Global Historic Climatologic Network (GHCN) as well as Global Summary of the Day (GSOD). These data will be analyzed to obtain the trends of mean, minimum and maximum temperatures for January and July. The trend in the change in total annual precipitation will also be reported.

The paper is organized in the following manner. At first, the criterion of the selection of the data will be discussed. The inclusion and exclusion criterion will be explained. In presentation of the results, the state of the temperature and precipitation in the year 2010 will be discussed first, and then the change of the temperature and 
precipitation over the last century will be presented.

\section{Material and Methodologies}

Before you begin to format your paper, first write and save the content as a separate text file. Keep your text and graphic files separate until after the text has been formatted and styled. Do not use hard tabs, and limit use of hard returns to only one return at the end of a paragraph. Do not add any kind of pagination anywhere in the paper. Do not number text heads - the template will do that for you.

Finally, complete content and organizational editing before formatting. Please take note of the following items when proofreading spelling and grammar:

Observational data records GHCN and GSOD at the National Climate Data Center of NOAA have been used in this study. Both datasets are available at https://www.ncdc.noaa.gov/. Records for temperature have been used from both the datasets, and the records for precipitation has been used from GHCN dataset only. Statistical tools have been applied to these time-series data sets to ascertain the centennial trend of climate change. Zweirs \& von Storch [43] have elaborated on the application and appropriateness of statistics as an investigative tool for climate change research. But, before these tools could be applied, the datasets had to be selected correctly for appropriateness of the statistical procedure.

The archives of the data sets used in this study are of different lengths for each element in set. Within the GHCN dataset, records of daily maximum and minimum temperatures start from the year 1840; record of daily mean temperature starts from 1701; while the record of precipitation starts from 1697. On the other hand, all records in the GSOD data start from 1929. In addition, the number of data-available stations also varies with year. The variation of the number of data-available stations for both GHCN and GSOD datasets from the years 1900 to 2010 are shown in Figure 1. This figure shows the availability of temperature data. The figure shows that the data availability for GHCN dataset increases uniformly from 1900, and drops drastically from 1990. On the other hand, the availability of GSOD dataset increases uniformly from 1929, but drops again, uniformly and drastically, from 1960 till 1970. Beyond 1970, the availability of the data increases continuously, with a small drop once again around the year 2000. Therefore, in addition to variation in the available length of the data record, many stations have data missing data for few years before the record resumes again. With such a variation in the data-availability, it was necessary, at first, to decide upon a data selection criteria.

An appropriate length for time-series analysis for climate change has been a point of discussion for a very long time. Part of the problem is that, historically, record keeping of climate variable did not start, in an organized manner, sufficiently long ago for an effective assessment of climate change. Nevertheless, some researchers have used the available data to report on climate change. Reiter, Weidinger \& Mauser [44] have used data records from 1960 to 2006 to comment on the change of climate in a particular part of Germany; Raha et al. [45] have used data from 1924 to 2008 to report on the impact of climate change on Indian Sunderban forest; twenty

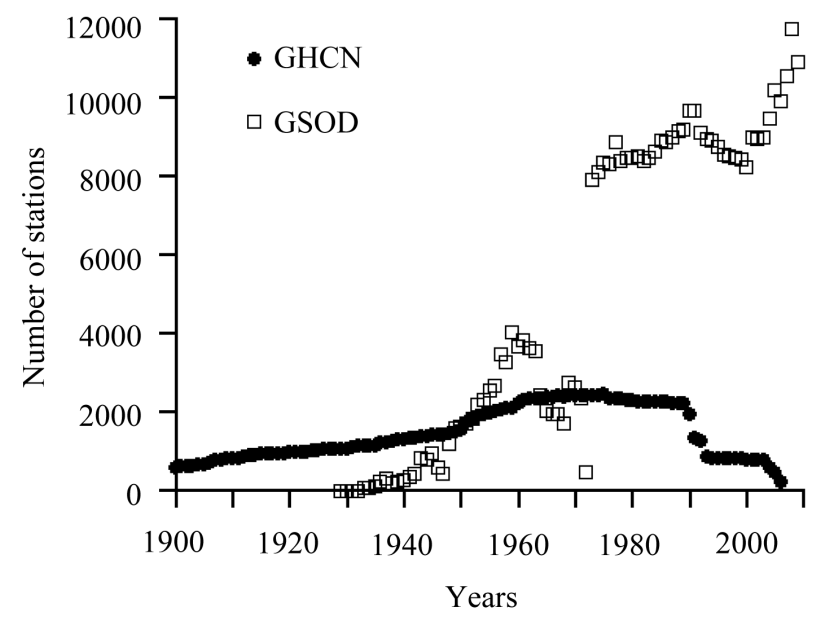

Figure 1. Variation of the number of data-available stations on GHCN and GSOD with years. 
nine years of data was used by Martínez et al. [46] to ascertain the trend in daily maximum and minimum temperatures in Catalonia, Spain. In these recent, and other studies different lengths of data records have been used in research on climate change [47]-[49]

The principal objective of this study is to ascertain the trend of global climate change over the last century. Therefore, it is necessary to choose stations from all over the world, and with sufficient length of data that would make the results credible. In order to do this, two major considerations was kept in mind. First, the length of the time series from a start year till the end year; and second, the number of years of missing data between the start year and the end year. Therefore to choose a credible data plan, three models were considered, and tested. These are

1) at least thirty years of record from start year till end year, with a maximum of ten years of missing data in between (effectively, 20 years of data);

2) at least forty years of record with a maximum of ten years of missing data in between; and

3) at least fifty years of record with a maximum of ten years of missing data in between.

After investigation, it was observed that the results of model 1) differs considerably with that of model 2); on the other hand results of models 2) and 3) were substantially similar to each other. Therefore the results presented in this research have been obtained with the second model.

Further considerations were needed in selection of a particular year as part of the time series of a station. The GSOD dataset provides record of daily data. In many cases some records of daily data is missing. Therefore, for a month under consideration, if ten days of data was missing, the month was kept out of analysis.

It was also noticed that because of historical reasons, some stations recording the data had moved geographically to a newer location. In this case, the data record from the old station was discontinued; a new WMO (World Meteorological Organization) identification was issued to the new station, and a new record was started. Furthermore, in many locations there are data records from two very nearby stations (e.g. weather bureau, and a local airport). Keeping these considerations in mind, temperature records from stations within 5 kilometers of each other were clustered together as one station; hence into one time series. With these selection criteria, the global number of stations considered for the mean temperature was 6428; for maximum and minimum temperatures were 5336. The numbers are same for both July and January.

A little different selection criterion was used for the precipitation data. The objective in this study is to look into the centennial variation of the total annual precipitation. It was observed GHCN record has enough data records in terms of number of years and number of stations for making a sensible assessment of the centennial change of precipitation. Therefore the precipitation record from GSOD was not considered in this study. For precipitation, the GHCN records provide total monthly precipitation data. In this case also, for some stations, precipitation records are missing for some months. In this case, that entire year was kept out from further analysis of the particular station. This means that if total precipitation for all twelve months were available, only then, these were added to obtain the total annual precipitation. The length of the time series was considered in the same manner that has been explained for temperature-a minimum of forty years of record from start year to end year with a maximum of ten years of record missing in between. Finally, the precipitation data were not clustered geographically according to their locations, as was done for the temperature data; as historically it is observed that rainfall at two nearby stations can vary substantially. With these selection criterions, a total of 10,733 stations were considered for global analysis of centennial change in precipitation.

Therefore, in final consideration, for each station, the time series for temperatures and precipitation are of different lengths; sometimes with data missing for some years in between. Figure 2 shows the characteristics of the time series for mean and maximum temperatures, and precipitation, those were considered in this study. The characteristics for maximum and minimum temperatures are not shown separately; similarly the characteristics for January and July are not shown separately, as they were observed to be similar in nature. Figure 2(a) shows the characteristics for the mean temperature; Figure 2(b) shows the characteristics for the maximum temperature; and Figure 2(c) shows the characteristics for precipitation. This figure shows two informations related to the length and data availability of the time series. First, the figure shows the frequency of the length of the time series (vertical bars); second it also shows the average number of years of data-availability for a particular length of time-series (dots). As an example, Figure 2(b) shows that for maximum temperature, there were approximately 800 stations whose length of time-series were from 60 to 65 years (vertical bars) reading values from the axis on the left. The dots show that on average there were approximately 58 years of data available in this length of time-series-reading values from the axis on the right. 


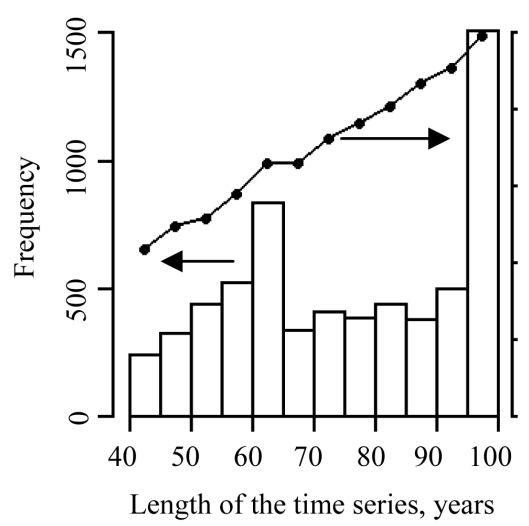

(a)

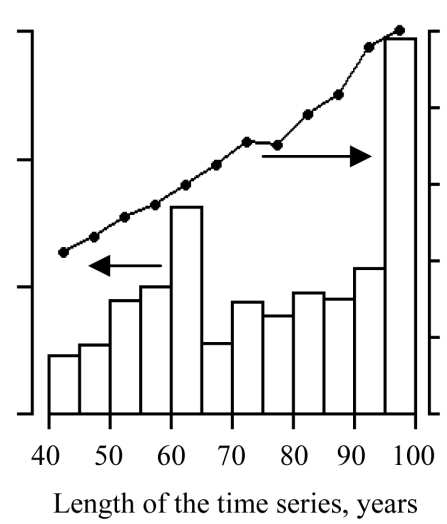

(b)

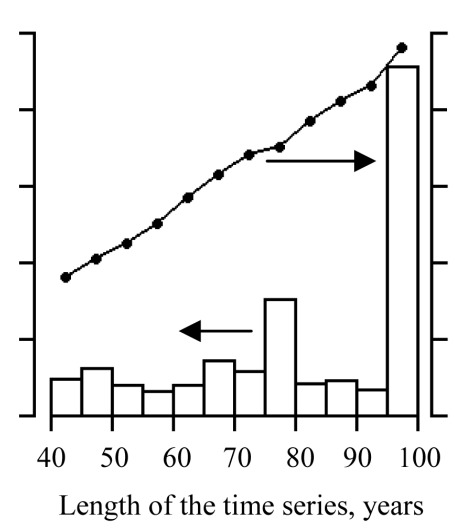

(c)

Figure 2. Characteristics of time-series of temperature and precipitation. (a) Mean temperature; (b) Maximum temperature; and (c) Precipitation.

The figure shows that though a minimum of 40 years of data was considered in the time series, the length of most time series are substantially higher with a large number of stations having a length more than 60 years. Moreover, the length of data availability is also very close to the length of the time series. This means that missing data in the time series is not going to have any significant effect on the overall results of the analyses.

A least-square linear regression model was used with the time series of temperatures and precipitation data to ascertain the change over the last century. The linear fit was used to obtain the extrapolated temperatures for the years 1900 and 2000. Linear regression is a standard technique that has been used by researchers to model climate data. In a review paper on the role of statistics in climate research, Zwiers \& Storch [43] refers other investigations [50]-[54] to claim that climate change problem can be statistically modeled as a linear regression problem. In this regards, Seidel \& Lanzante [55] tested three different linear models on some selected temperature data. These were standard linear model, piecewise linear model, and sloped stepped model. Though the models performed differently within the range of data, but had no impact on the end points of the time series. Other researchers have also used a linear model to investigate the change in climate [42] [56].

The statistical distribution and the geographical nature of global temperatures during July and January will be discussed. Similarly, the statistical distribution and geographical nature of the change in temperature from 1900 till 2000 will also be reported. Finally, statistical distribution and the geographical nature of the annual precipitation and its change would also be discussed.

\section{Results and Discussion}

Before the results of the change of climate are presented, the present states of some temperature and total annual precipitation are presented.

\subsection{Temperature in 2010}

Figure 3 shows the global distribution of the daily maximum temperatures in July and January in 2010. The maximum and minimum temperatures did not present any significance difference in the global distribution for either January or July. Hence they have not been shown separately, and only the maximum temperatures are displayed in Figure 3. Applying all the selection criterion stated in the last section, a total of 8036 stations are displayed in Figure 3.

Global distribution of temperatures in Figure 3 shows an overall nature that has been well discussed earlier in other studies. In Figure 3(a), during January, the continuous region of northern to eastern Russia and continuing to central China, and northern Canada are the coldest region on earth. On the other hand, almost the entire belt in the southern hemisphere is the warmest region. On the other hand, during July, as appearing in Figure 3(b), eastern parts of China, north Africa, middle east, parts of eastern US are some of the warmest regions, and southern parts of South America and south Australia are some of the coldest regions on earth. The general nature of the global distribution observed here is consistent with observations reported earlier. 


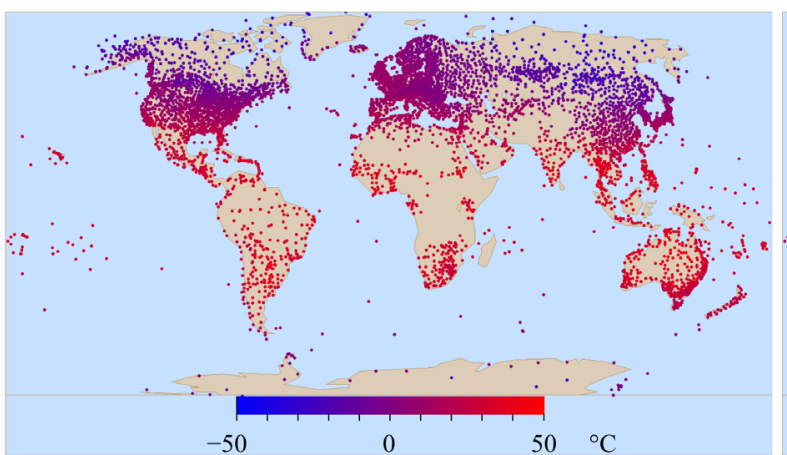

(a)

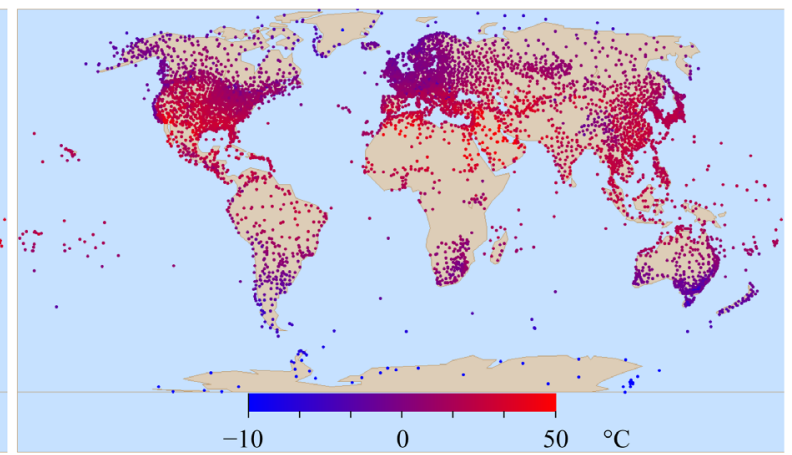

(b)

Figure 3. Global distribution of daily maximum temperatures in January and July in 2010. (a) Mean daily maximum temperature in January; (b) Mean daily maximum temperature in July.

Figure 4 shows the histogram of the daily maximum and minimum temperatures in January and July obtained from all the stations. Figure 4(a) \& Figure 4(b) shows the histogram of maximum and minimum temperatures in January; and Figure 4(c) \& Figure 4(d) shows the similar results for July. It is observed remarkably that most of the histograms in Figure 4 are bimodal. This indicates that possibly there are two different systems of temperatures those are generating the two modes in the histograms. To identify these systems, it was attempted to identify the geographical regions those are generating these different parts. As an example, the procedure is explained for daily minimum temperature in January shown in Figure 4(b) and July shown in Figure 4(d). Figure 4(b) \& Figure (d) shows that the two modes in the temperature histogram appear approximately at $10^{\circ} \mathrm{C}$ and $18^{\circ} \mathrm{C}$ respectively. Geographical regions with temperature larger than these temperatures are shown in Figures 5(a) for daily minimum temperature in January, and Figure 5(b) for daily minimum temperature in July. It is clear from Figure 5 that the different modes in the temperature histograms are being generated by records from different ranges of latitudes. The lower modes in the histograms are generated from temperatures in a geographical region above a particular north latitude, and below a south latitude; referred in this paper as the non-tropical region. Similarly, the second modes of the histograms are generated from temperatures within a north and south latitude; referred to in this paper as the tropical region. Approximations of these latitudes were identified from Figure 5, and histograms for the temperatures of each of these regions were generated separately. These histograms are shown in Figure 6. They reveal that for all the four histograms, the tropical and non-tropical regions result in histograms those are very similar in nature. Both geographical regions have temperature distributions those are strongly negatively skewed. The negative skewness of daily temperature observed here is consistent with the observations reported earlier [57] [58].

Figure 6 also reveal that the tropical regions for the histograms are different in January than in July. During January, shown in Figure 6(a) \& Figure 6(b), the tropical region is bounded within $30^{\circ} \mathrm{N}$ and $45^{\circ} \mathrm{S}$ latitudes. On the other hand, during July, the tropical region almost reverses and is bounded within $45^{\circ} \mathrm{N}$ and $25^{\circ} \mathrm{S}$ latitudes. It is believed that this behavior of temperatures is arising from atmospheric movement associated with Hadley circulation [58]. Because of its importance in determining the nature of global climate, Hadley circulation is being extensively studied [59]-[61]. It is suspected that Hadley circulation influences climate change and vice versa [62] [63].

To see the similarity between the histograms of the two geographical regions, the respective histograms of each region are plotted in Figure 7 as standard temperature, $\left(T-T_{m}\right) / \sigma_{T}$, where $T$ is the temperature, $T_{m}$ is the mean temperature, and $\sigma_{T}$ is the standard deviation of the temperature. Remarkably, for most of these histograms, the histograms of the tropical regions and the non-topical regions are very similar to each other. The similarity and the differences between these histograms can be better understood from the skewness and kurtosis, given in Table 1. We can put these results in a better perspective keeping in mind that the skewness and kurtosis of a normal distribution are 0.0 and 3.0 respectively. Table 1 indicates that in Figure 7, for January, the tropical and non-tropical regions have skewness those are negative, and are similar to each other-more negative in the non-tropical region, and less negative in the tropical region. The kurtosis of all the histograms for January are close to 3.0; i.e. the kurtosis for normal distribution. The situation for July is quite different and slightly more complicated. For the maximum temperature in July, the skewness is very low for both tropical and non-tropical 


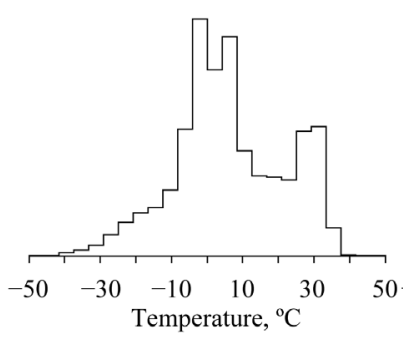

(a)

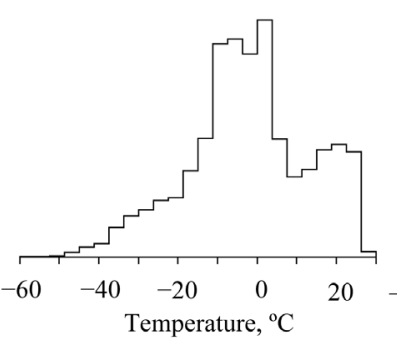

(b)

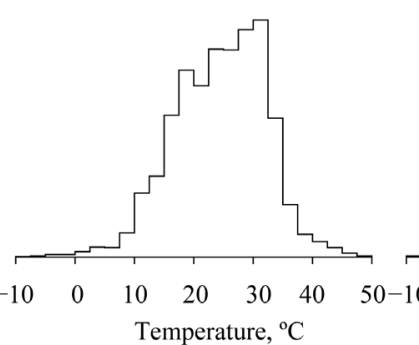

(c)

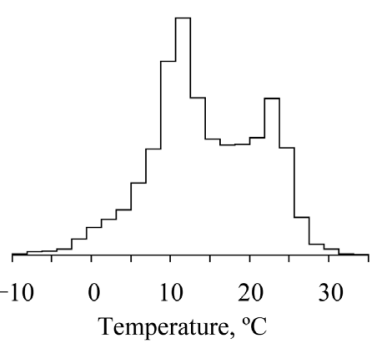

(d)

Figure 4. Histograms of daily maximum and minimum temperatures in January and July. (a) Daily maximum temperature, January; (b) Daily minimum temperature, January; (c) Daily maximum temperature, July; (d) Daily minimum temperature, July.

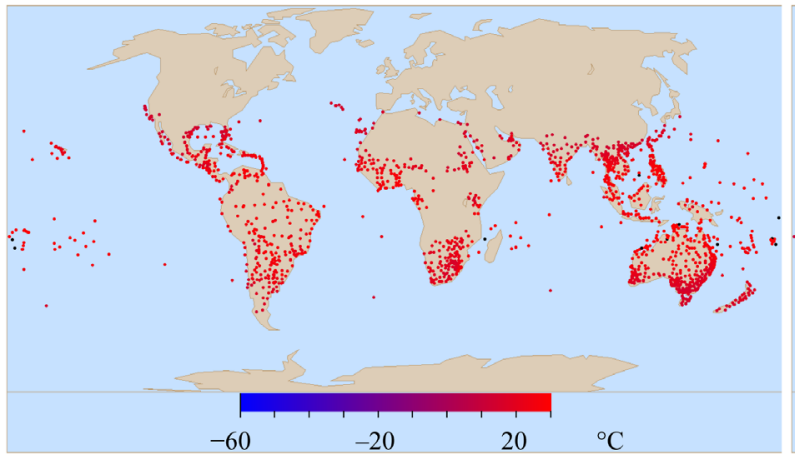

(a)

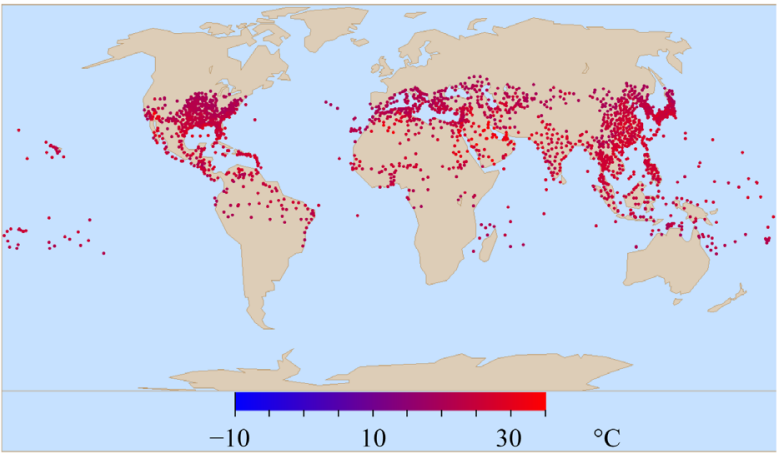

(b)

Figure 5. Geographical distribution of one of the modes of daily minimum temperatures in January and July. (a) Mean daily minimum temperature greater than $10^{\circ} \mathrm{C}$ in January; (b) Mean daily minimum temperature greater than $18^{\circ} \mathrm{C}$ in July.

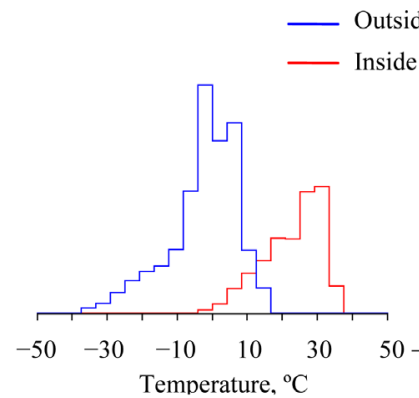

(a)
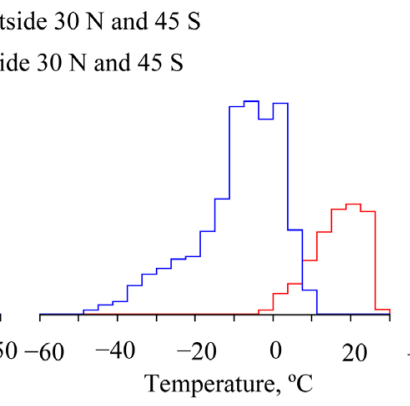

(b)

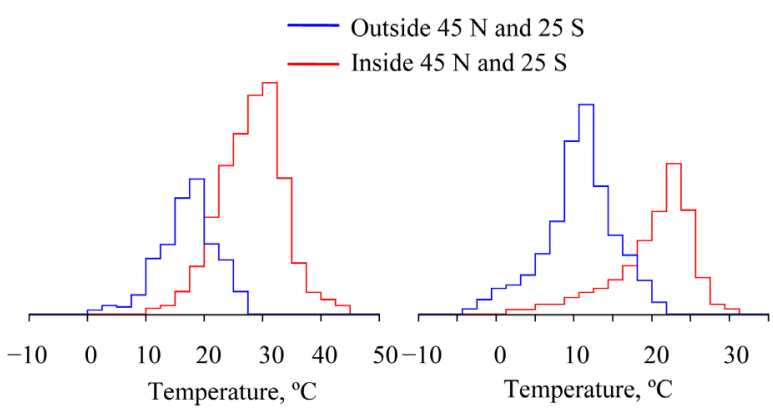

(c)

(d)

Figure 6. Histogram of daily maximum and minimum temperatures in January and July shown separately for different geographical regions. (a) Daily maximum temperature, January; (b) Daily minimum temperature, January; (c) Daily maximum temperature, July; (d) Daily minimum temperature, July.

regions. This means that the histograms are close to being symmetric. On the contrary, for the minimum temperature in July, the skewness is high for the tropical regions, but in the non-tropical region, the skewness is of the same order of magnitude as the skewness for maximum temperature. The kurtosis of the histograms for both maximum and the minimum temperatures in the tropical regions is similar to that of a normal distribution. But the kurtosis of the histograms for the non-tropical regions for both the maximum and minimum temperatures are substantially lower; indicating that the distributions have prominent peaks along the middle. These similarities and differences between the temperatures in the tropical and non-tropical regions point out to the similarities and differences between the physical processes in these regions. This can substantially influence the understanding used for modeling global climate. 


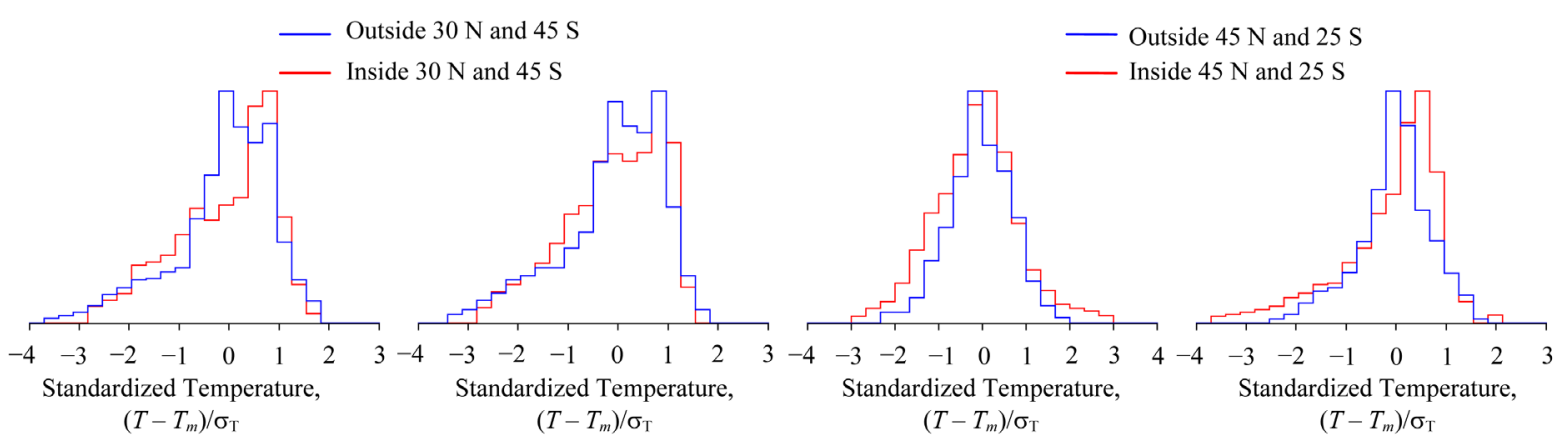

(a)

(c)

(d)

Figure 7. Histogram of daily standardized maximum and minimum temperatures in January and July shown separately for different geographical regions. (a) Daily maximum temperature, January; (b) Daily minimum temperature, January; (c) Daily maximum temperature, July; (d) Daily minimum temperature, July.

Table 1. Skewness and kurtosis of histograms of temperatures.

\begin{tabular}{cccc}
\hline \multirow{2}{*}{ Maximum Temperature, January } & & Skewness & Kurtosis \\
& Inside the tropics & -0.778 & 3.010 \\
Minimum Temperature, January & Outside the tropics & -0.932 & 3.786 \\
& Inside the tropics & -0.647 & 2.726 \\
Maximum Temperature, July & Outside the tropics & -0.923 & 3.464 \\
& Inside the tropics & -0.215 & 1.390 \\
Minimum Temperature, July & Outside the tropics & -0.164 & 3.942 \\
\hline
\end{tabular}

Besides understanding the trend of a physical quantity, histograms are also used to obtain point estimators like mean, standard deviation, etc. Therefore, we can obtain an estimate of the mean temperature in 2010 both from the histograms in Figure 5 as well as from the histograms in Figure 7. Remarkably, if the histograms in Figure 5 are used with the entire earth as a single system, the mean temperatures in January and July are obtained as $3.46^{\circ} \mathrm{C}$ and $20.02^{\circ} \mathrm{C}$ respectively. But if the histograms of different regions, as shown in Figure 7 , are considered with their respective geographical areas, the mean temperature in January and July are obtained as $10.48^{\circ} \mathrm{C}$ and $21.48^{\circ} \mathrm{C}$ respectively. It is clear that the two estimates are substantially different.

\subsection{Precipitation}

The histogram of global annual precipitation and its geographical distribution in 2010 are shown in Figure 8(a) \& Figure 8(b) respectively. Almost 11,000 stations, globally, have been considered in these figures. Figure 8(a) shows that the global histogram of total annual precipitation is strongly positively skewed. Earlier, Kharin et al. [63] has also reported that the global precipitation follows a strong positive skewness. Though there are stations those have annual precipitation in the range of 400 centimeters, but more than $85 \%$ of stations have precipitation within 150 centimeters. Therefore, very few locations in earth have extreme precipitation conditions. Figure 8(b) shows these regions of extreme precipitation. This figure shows that regions of northwestern Canada, Central America continuing to northern boundaries of South America, along Sierra Leone and Cameroon coast in Africa, along Western Ghats and northeastern parts of India and the regions extending from Southeast Asia to southcentral Pacific have high level of precipitation.

\subsection{Centennial Change in Temperature}

After presenting the present state of temperature and total annual precipitation in the last section, their changes over the last century are presented in this section. The histograms of the maximum and minimum temperatures 


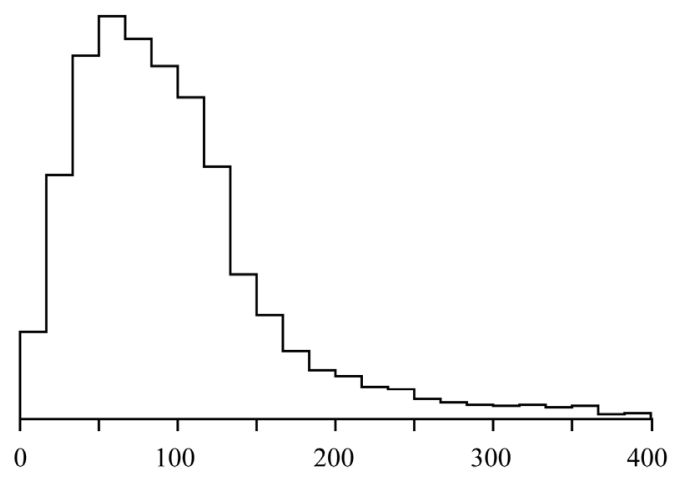

(a)

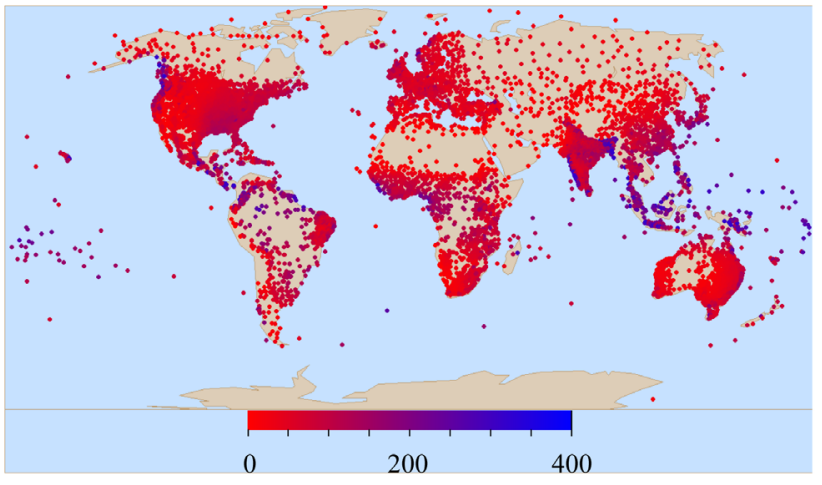

(b)

Figure 8. Global histogram and geographical distribution of total annual rainfall. (a) Total annual rainfall, cm; (b) Global distribution of total annual rainfall, $\mathrm{cm}$.

in 1900 and 2000 for the months of January and July are presented in Figure 9. The histograms for the year 1900 and 2000 are presented in blue and red, respectively. The general nature the histograms are similar to the histograms for the year 2010 presented in Figure 4. Similar to the observation in Figure 4, all the histograms in Figure 9 are bimodal. Earlier, this behavior was attributed to Hadley circulation occurring in different regions of the earth. The histograms of Figure 9, separated for these different regions of the earth are shown in Figure 10. Similar to Figure 6, the histograms of the two separated regions in Figure 10 are similar to each other. This is observed for both 1900 and 2000. This indicates that possibly between 1900 and 2000, there may not have been any substantial change in the structural nature of the Hadley circulation. There have been several recent investigations [60] [62] [64] to ascertain the impact of climate change on Hadley circulation. The results appearing in Figure 10 do not point to any substantial change in the regions associated with these circulations.

The result that is clearly demonstrated in Figure 9 is that in all the four histograms, the distributions for the year 2000 has shifted to the right compared to the distributions for the year 1900. This is a clear indication that the mean temperature in the year 2000 has increased compared to that in 1900. The shifts in the histograms are such that there are no substantial changes along the two ends of the histograms. The dominant shift is along the middle of the histograms. This means that from 1900 to 2000, there is no dominant change in the extremes of global temperatures. The dominant changes in the distributions of the temperature take place as a positive shift around the peak of the distributions. Figure 10 further shows that these behaviors remain similar even if the histograms are considered separately for regions within the tropics, and regions outside the tropics.

The histograms of the global centennial change of maximum and minimum temperatures in January and July are shown in Figure 11. The statistical measures of these histograms are given in Table 2. The standard deviation shows that the variation and range of the global centennial temperature change is substantially higher in January than in July. This is a reflection of the trend in the change histogram that the temperature change ranges from $-10^{\circ} \mathrm{C}$ to $15^{\circ} \mathrm{C}$ in January; whereas it ranges from $-5^{\circ} \mathrm{C}$ to $10^{\circ} \mathrm{C}$ in July. This indicates that the temperature change for January is more widely distributed than July.

To discuss the skewness and kurtosis, once again, for reference, the skewness and kurtosis of a normal distribution are 0.0 and 3.0 respectively. Table 2 reveals that both skewness and kurtosis of the change in maximum and minimum centennial temperatures in January are around 0.5 and 3.65 respectively. This indicates that the distribution of the global centennial temperature change for the maximum and minimum temperatures are almost similarly skewed and similarly distributed across the range. Despite the positive skewness, Table 2 also indicates that the kurtoses of the maximum and minimum centennial temperature changes in January are not too different than that of a normal distribution.

The skewness and kurtoses of global centennial change of maximum and minimum temperatures for July shown in Table 2 show a different trend than those for January. The skewness for both the maximum and minimum centennial temperature changes are positive, but are quite different than each other. The skewness for maximum global centennial temperature change is quite lower than that for the minimum temperature. This means that there is a tendency for the centennial change of minimum temperature in July to be more positive 


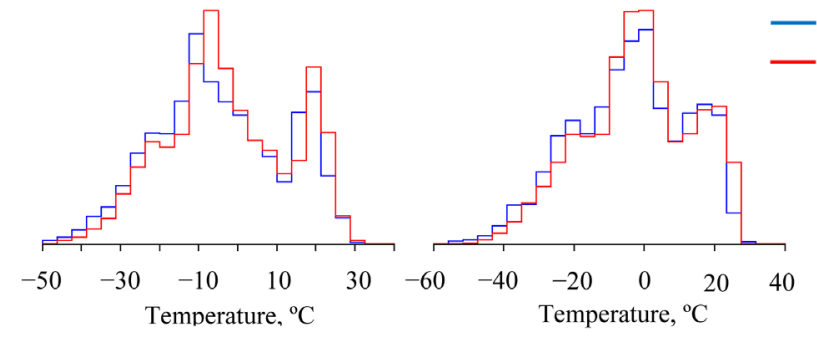

(a)

(b)

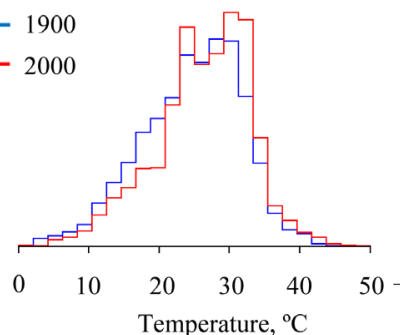

(c)

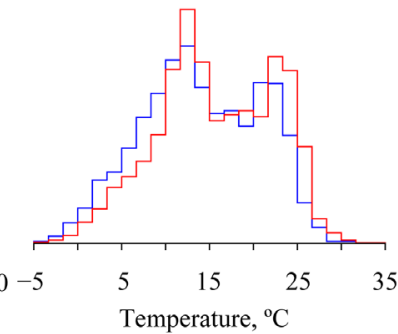

(d)

Figure 9. Histogram of daily maximum and minimum temperatures in January and July for the years 1900 and 2000 . (a) Daily maximum temperature, January; (b) Daily minimum temperature, January; (c) Daily maximum temperature, July; (d) Daily minimum temperature, July.

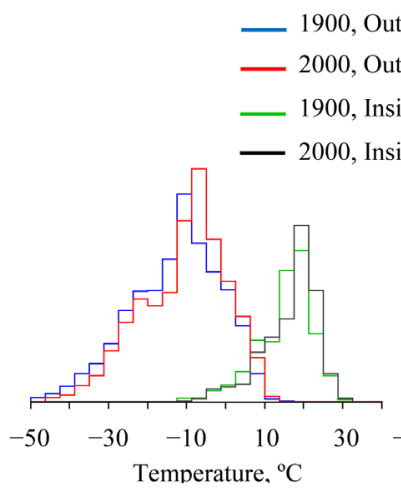

(a)
Outside $30 \mathrm{~N}$ and $45 \mathrm{~S}$

$30 \mathrm{~N}$ and $45 \mathrm{~S}$

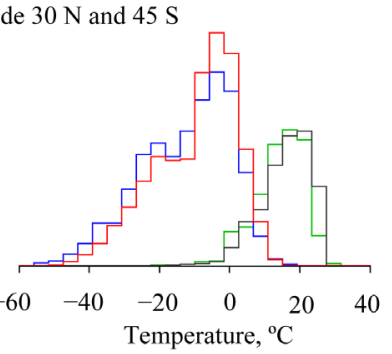

(b)

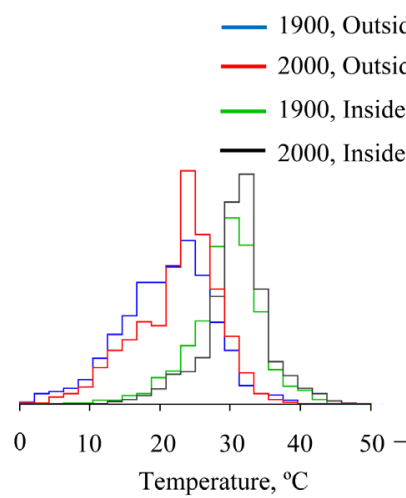

(c)
- 1900, Outside $45 \mathrm{~N}$ and $25 \mathrm{~S}$

Outside $45 \mathrm{~N}$ and $25 \mathrm{~S}$

$45 \mathrm{~N}$ and $25 \mathrm{~S}$

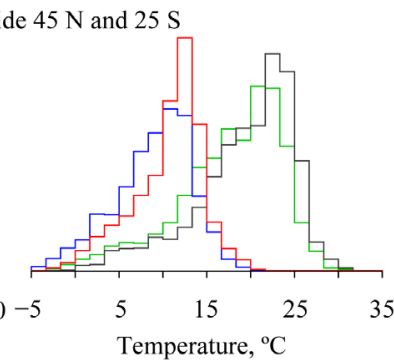

(d)

Figure 10. Histogram of daily maximum and minimum temperatures in January and July for the years 1900 and 2000 , shown separately for different geographical regions. (a) Daily maximum temperature, January; (b) Daily minimum temperature, January; (c) Daily maximum temperature, July; (d) Daily minimum temperature, July.

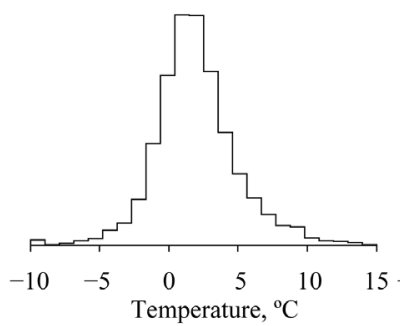

(a)

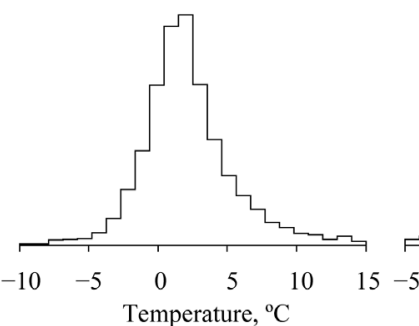

(b)

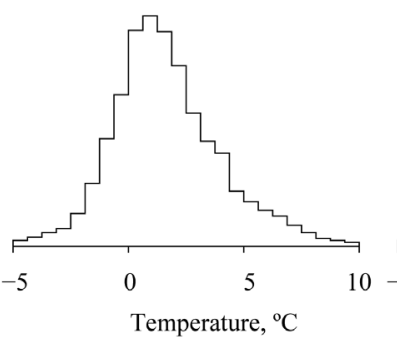

(c)

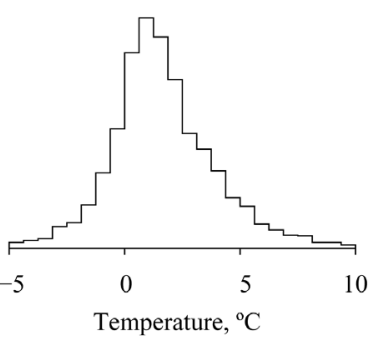

(d)

Figure 11. Histogram of daily maximum and minimum temperatures increase in January and July between the years 1900 and 2000. (a) Maximum temperature increase, January; (b) Minimum temperature increase, January; (c) Maximum temperature increase, July; (d) Minimum temperature increase, July.

Table 2. Statistical measures of histograms of centennial increase in temperatures.

\begin{tabular}{ccc}
\hline & Standard deviation & Skewness \\
Maximum Temperature, January & 2.974 & 0.503 \\
Minimum Temperature, January & 3.291 & 0.470 \\
Maximum Temperature, July & 2.332 & 0.334 \\
Minimum Temperature, July & 2.223 & 0.660 \\
\hline
\end{tabular}


compared to other centennial temperature changes. On the other hand the kurtoses of the maximum and minimum global centennial change of temperatures are very similar to each other, but substantially higher than the kurtosis for a normal distribution. This indicates that the distributions of temperature change are more spread than a normal distribution.

Figure 11 also indicates the centennial global temperature change was positive in most locations over the last century. Nevertheless, there are certain locations, globally, where the temperature change was negative. The figure indicates that for maximum and minimum temperatures in January, and for maximum temperature in July, globally, the temperature has reduced in approximately $22 \%$ of the stations; whereas, the temperature has reduced for approximately $19 \%$ of the stations for minimum temperature in July. This indicates that, the minimum temperature in July rose more compared to the temperatures in January and maximum temperature in July.

The geographical distributions of the centennial global change of temperatures are shown in Figure 12. Once again, there was minimal difference in the geographical natures of the minimum, maximum and the mean temperatures in both January and July. Therefore, only the geographical distributions of the mean temperatures are shown in Figure 12. The change of temperature for January, shown in Figure 12(a), shows that the temperature rose most in a region starting from central Europe to western Russia and parts of eastern Russia and northern China. Northern parts of Canada also show increased temperature rise. The United States shows an interesting trend in temperature change. The west coast indicates quite substantial temperature rise, whereas the east coast shows the temperature in January has reduced over the last century. Other parts of the earth where the temperature change has negative trend are central Russia, southeast Australia, central Africa and parts of central China.

The geographical nature of temperature change in July appearing in Figure 12(b) shows that the maximum temperature change occurred in a large belt starting from Pakistan continuing through the Middle East all the way to the northern and southern coast of the Mediterranean Sea. Other regions of high temperature change are central China and the region bordering western Russia and Scandinavia. Figure 12(b) also shows that the centennial temperature in July has reduced in regions around eastern China, central Russia, parts of southeast Australia, east coast of the US. The general nature of these observed global centennial temperature change are in general agreement with the simulation reported by Hansen et al. [65]. It should be mentioned that earlier simulations results, though, are available as annual change of mean temperature. The present work reports the changes of maximum and minimum temperatures for January and July separately. Therefore, complete agreement with previous simulation results is not expected.

One of the primary objectives of climate research in the past was to obtain an estimate of the change in temperature. Several simulation experiments in the past have provided widely varying estimate for the temperature rise for the last century. Estimates provided by IPCC range from $0.3^{\circ} \mathrm{C}$ to $6.4^{\circ} \mathrm{C}$ [8]. In this study, estimate of centennial temperature change would be obtained using the temperature histograms in Figure 9 \& Figure 10, as well as using the temperature change histogram in Figure 11. Before, these results are presented, it is necessary to discuss several issues related to use of these figures to find the temperature change. After all the data and procedural validation, the global distribution of stations those are included in this study, are not uniformly distributed around the globe. Figure 3 and Figure 12 shows that there are relatively fewer stations in South America, Africa, central Australia, Middle East, central Asia and western China. In addition, there are also relatively

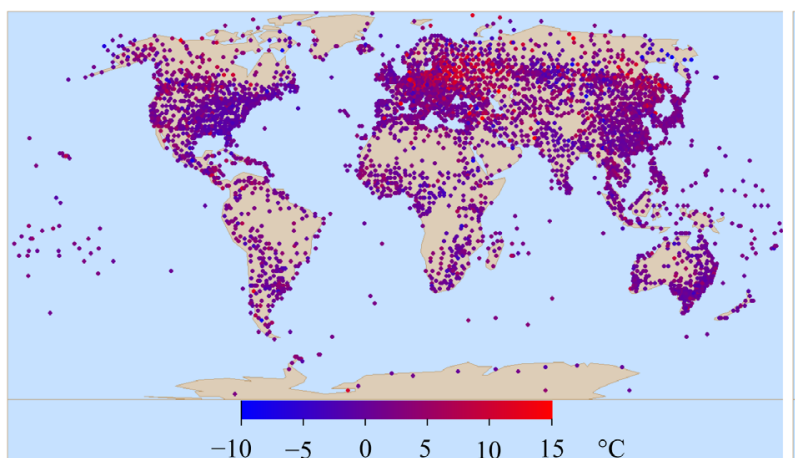

(a)

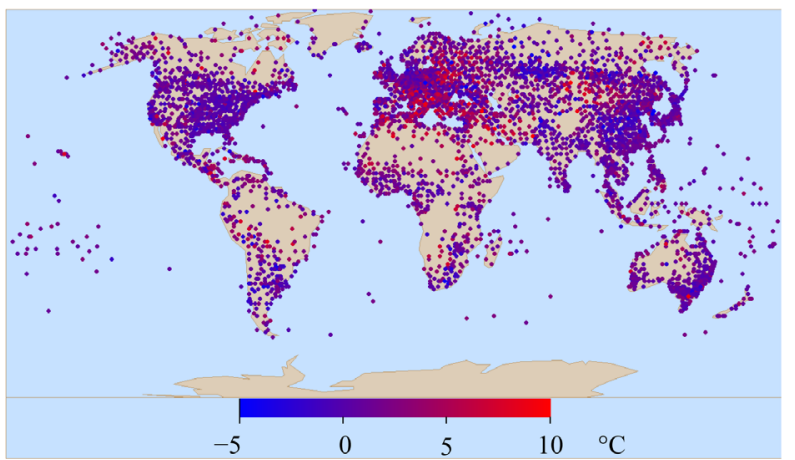

(b)

Figure 12. Geographical nature of the change in the mean temperature from 1900 to 2000 during January and July. 
fewer stations in northern Canada, and northern Russia. In light of this, if we take a simple statistical mean of the data from the histograms in Figures 9-11, the results are likely to be biased. On the other hand, Figure 6 demonstrates that the temperatures at all stations, globally, can be considered into two different regions resulting in two different self-similar histograms. Therefore, it can be argued that even if data from more stations are included, because of the self-similar nature of the histograms, there may not be much difference in the mean calculated from the histograms. Furthermore, it was observed that the self-similar histograms of the two different regions are strongly skewed negatively. As a result, the mean calculated as a central tendency from the histogram is likely to be biased by the skewed values. In these situations, the median gives a better measure of the central tendency.

Consequently, in this study, separate estimates of global centennial temperature change would be reported here using different data sets:

(a) arithmetic mean would be obtained from temperatures in the year 1900 and 2000 at all locations, globally; hence change in temperature;

(b) arithmetic mean would be obtained from temperatures in the year 1900 and 2000, considered separately from tropical and non-tropical regions; mean would be obtained considering the global areas of these two regions;

$(c),(d)$ procedures mentioned in $(a)$ and $(b)$ are repeated with the median;

(e) temperatures from all stations in a spherical square on the surface of the earth of one degree latitude and one degree longitude are lumped into one temperature record; arithmetic mean of temperatures in 1900 and 2000 are obtained using these temperatures, weighted with the areas of corresponding spherical square; hence the change in temperature;

$(f)$ procedure in $(e)$ is repeated separately for tropical and non-tropical regions as described in procedure $(b)$;

$(g)-(j)$ procedures in $(a),(b),(e)$ and $(f)$ are repeated using the records of change in temperature shown in Figure 11.

The above ten estimates of changes in centennial maximum, minimum and mean temperatures for January and July are reported in Table 3. In this table "Statistical" refers to the estimates $(a),(c),(e),(g)$ and $(i)$; and "In/Out" refers to the estimates $(b),(d),(f),(h)$ and $(j)$. "Mean" and "Median" refers to the methodology used to estimate the central tendency. To obtain a better understanding of these estimates, they are also shown graphically in Figure 13. Table 3 and Figure 13 give some very interesting insight into the nature of the temperature changes. The possibilities of some ambiguities regarding the estimation of the temperature change have been discussed earlier. But the results here indicate that all the ten estimates of each temperature change are very close to each other. It was suspected that uneven geographical distribution of measuring stations might have an impact on the estimation of the temperature change; Table 3 and Figure 13 shows that it does not. It was also suspected that the effect of Hadley circulation might have an impact on the estimation of the temperature change; the results indicate that there is no substantial impact. It was further construed that estimating the temperature

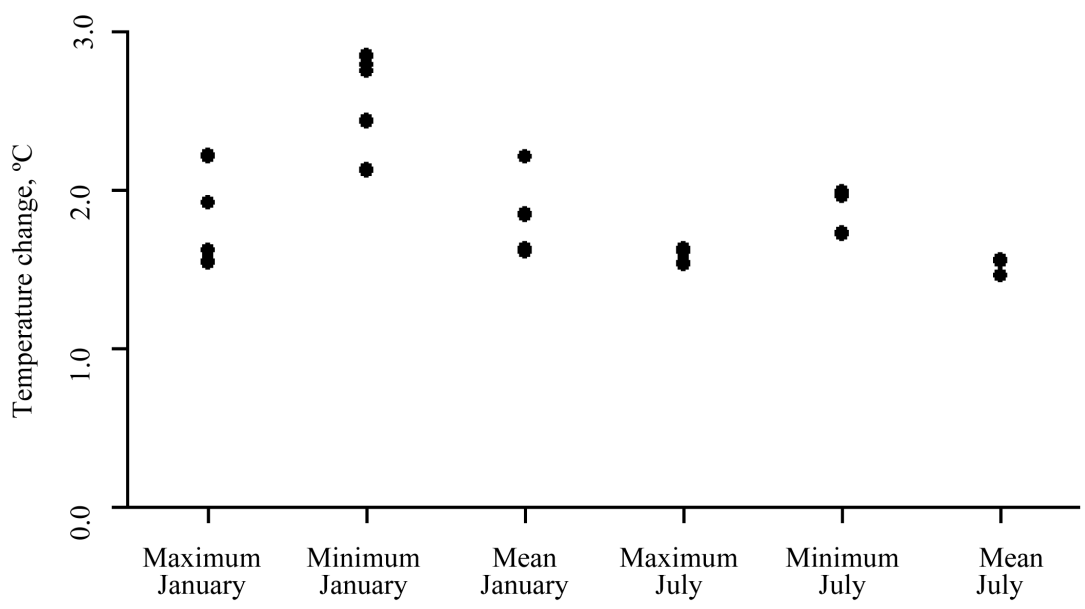

Figure 13. Different estimates of global centennial temperature change for January and July. 
Table 3. Estimate of global centennial change of temperature, $1900-2000\left({ }^{\circ} \mathrm{C}\right)$.

\begin{tabular}{|c|c|c|c|c|c|c|c|c|c|c|}
\hline & \multicolumn{6}{|c|}{ Temperature histogram } & \multicolumn{4}{|c|}{ Temperature rise histogram } \\
\hline & \multicolumn{4}{|c|}{ Statistical } & \multirow{2}{*}{\multicolumn{2}{|c|}{ Area weighted }} & \multirow{2}{*}{\multicolumn{2}{|c|}{ Statistical }} & \multirow{2}{*}{\multicolumn{2}{|c|}{ Area weighted }} \\
\hline & \multicolumn{2}{|c|}{ Mean } & \multicolumn{2}{|c|}{ Median } & & & & & & \\
\hline & Global & In/Out & Global & In/Out & Global & In/Out & Global & In/Out & Global & In/Out \\
\hline Maximum Temperature, January & 1.922 & 1.622 & 1.961 & 1.628 & 2.211 & 1.150 & 1.922 & 1.622 & 2.222 & 1.156 \\
\hline Minimum Temperature, January & 2.444 & 2.128 & 2.672 & 2.217 & 2.850 & 2.800 & 2.439 & 2.133 & 2.856 & 2.750 \\
\hline Mean Temperature, January & 1.850 & 1.617 & 1.772 & 1.628 & 2.211 & 1.611 & 1.844 & 1.633 & 2.211 & 1.611 \\
\hline Maximum Temperature, July & 1.550 & 1.533 & 1.450 & 1.572 & 1.633 & 1.617 & 1.550 & 1.533 & 1.633 & 1.617 \\
\hline Minimum Temperature, July & 1.733 & 1.733 & 1.631 & 1.722 & 1.994 & 1.983 & 1.728 & 1.728 & 1.989 & 1.967 \\
\hline Mean Temperature, July & 1.467 & 1.467 & 1.561 & 1.722 & 1.556 & 1.556 & 1.467 & 1.461 & 1.561 & 1.561 \\
\hline
\end{tabular}

change using the temperature histograms for the year 1900 and 2000, and using the temperature change histogram might give us different estimates. There was no substantial change.

Table 3 and Figure 13 give an assessment about the level of centennial change of temperature. The different estimates for the change of maximum temperature in January range from $1.51^{\circ} \mathrm{C}$ to $2.2^{\circ} \mathrm{C}$; whereas the change for the minimum temperature in January range from $2.13^{\circ} \mathrm{C}$ to $2.85^{\circ} \mathrm{C}$. The mean of these estimates are $1.83^{\circ} \mathrm{C}$ and $2.55^{\circ} \mathrm{C}$ respectively. The ranges of the different estimates of these two temperatures are almost similar to each other.

The different estimates for the change in temperatures in July are almost similar to each other. The mean of these different estimates of changes in temperature are $1.58^{\circ} \mathrm{C}$ and $1.86^{\circ} \mathrm{C}$ for maximum and minimum temperatures respectively. These results also point out clearly that the temperature has clearly increased over the last century. Temperature in winter has risen more than that of summer. Moreover, the minimum temperature in winter has increased more than that of the maximum temperature in winter. Temperature rise in July also show the same trend that the minimum temperature has increased more than that of the maximum temperature. These estimates substantially narrow the range of temperature rise that has been predicted by IPCC [8].

\subsection{Centennial Change in Total Annual Precipitation}

The state of total annual precipitation in the year 2010 was presented in Figure 8. A comparison of the total annual precipitation for the years 1900 and 2000 is presented in Figure 14. The figure shows a comparison of histograms of total annual precipitation at all stations globally. Figure 14 shows that all the changes in the histogram has taken place in the lower end of the histogram-in stations with a total annual precipitation within 150 $\mathrm{cm}$. In this range, the histogram has skewed slightly positively. This means that number of stations with low precipitation has decreased, and comparatively, the number of stations with higher amount of precipitation has increased. Figure 14 also clearly indicates that there has not been any substantial change in the number of stations with extreme precipitation. These histograms were used to determine that the average precipitation in the year 1900 was 93 centimeters, and in the year 2000 was 95 centimeters. This indicates that precipitation has increased in the year 2000 compared to the year 1900. But because the histogram of total precipitation is strongly skewed, Kharin et al. [63] has argued that mean is not a very good measure of the central tendency, because it would be biased by the heavily skewed values of precipitation. Therefore, they have suggested the use of the median as a measure of the central tendency. Using Figure 14, the median precipitation was found to be 77 and 81 centimeters for the years 1900 and 2000 respectively. Therefore, the median indicates a greater increase in the precipitation than the mean.

The histogram for centennial change of total annual precipitation, and its geographical distribution are shown Figure 15. Figure 15(a) shows that histogram of the centennial change in total annual precipitation, and Figure 15(b) shows the geographical distribution of these changes. Figure 15(a) shows that the histogram for the centennial change in the total annual precipitation is almost symmetric with the precipitation reducing in half of the stations globally, and increasing in the other half. The change in the total annual precipitation varies from negative 100 centimeters to positive 100 centimeters. This means that the amount of reduction and increase in the total 


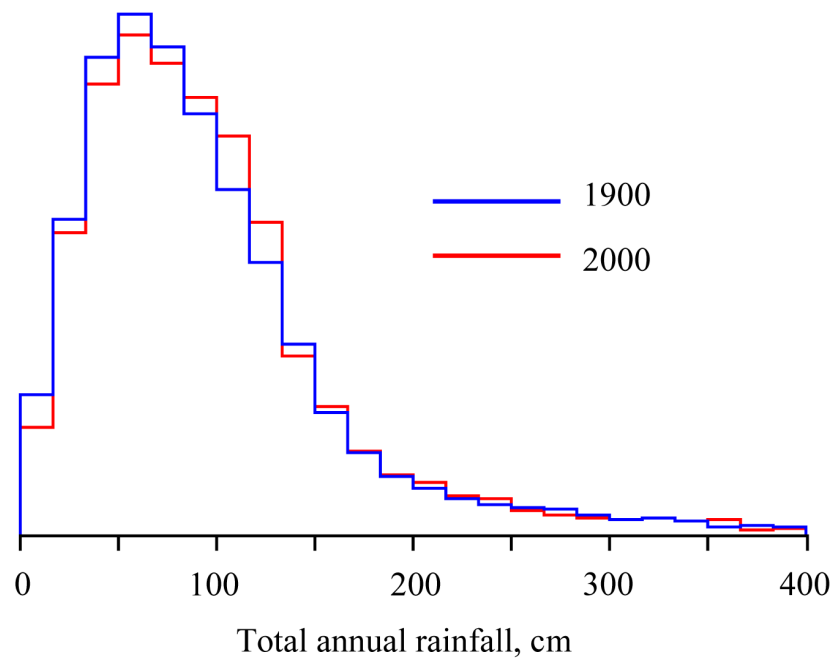

Figure 14. Histograms showing the geographical distribution of total annual rainfall for the years 1900 and 2000.

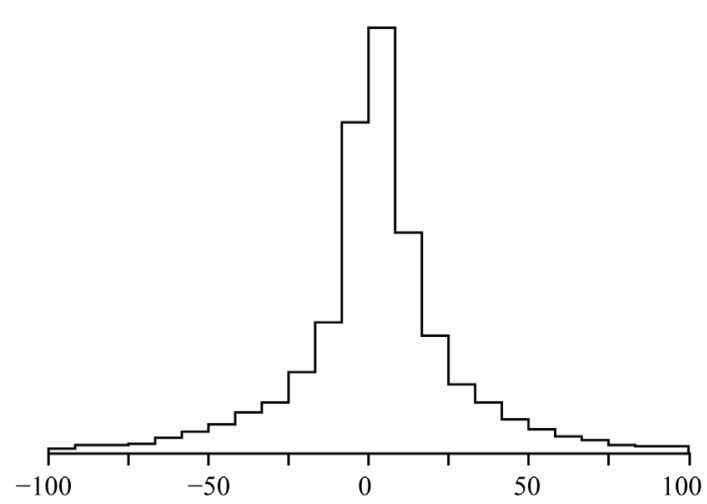

(a)

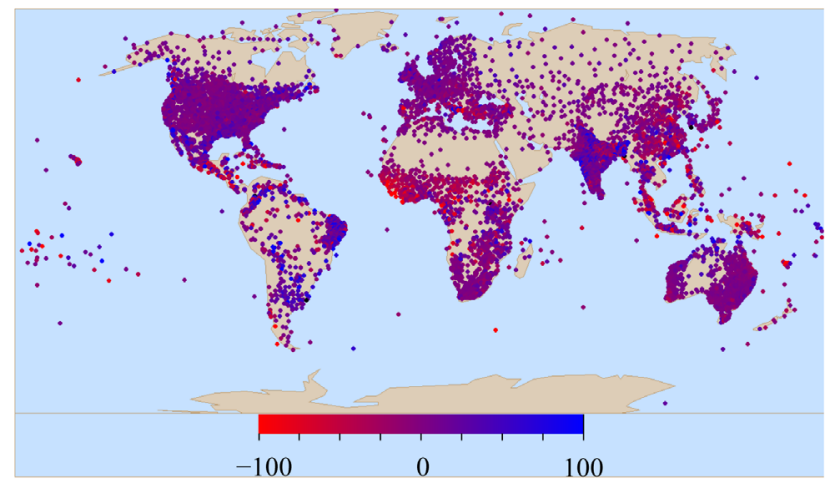

(b)

Figure 15. Histogram of the change in total annual rainfall, and its global geographical distribution. (a) Histogram; (b) Global distribution.

annual precipitation are almost equal, globally. Moreover, the histogram is very steep around zero, indicating that there is a considerable number of stations, globally, where there was minimal change in the total annual precipitation.

The geographical distribution of the change in total annual precipitation is shown in Figure 15(b). To understand the geographical nature of change of the total annual precipitation, Figure 15(b) would be compared with Figure 8(b) which showed the total annual precipitation in the year 2010. Figure 15(b) shows that the equatorial belt starting from Central America, the Caribbean, continuing to Africa from west to east, all the way to Southeast Asia are regions of extreme reduction in the total annual precipitation. Interestingly, Figure 8(b) indicates that these are part of the regions of highest precipitation, globally. Other regions of high reduction in precipitation are East Asia, and the region around the Mediterranean Sea.

Figure 15(b) also shows that the total annual precipitation has increased at many regions around the world over the last century. These regions include region around the Amazon forest in South America, region around the Gulf of Mexico, almost the entire western part of India, northeast part of India. Of these regions, Figure 8(b) shows that the west coast and northeast part of India are also regions where the total annual precipitation is high.

There are very few studies reporting on the long term change of precipitation. Most of the results appearing in the literature are short term result based on simulations. It is understood that the simulation of precipitation is more difficult than simulation of temperature. Nevertheless, the outlook for change in precipitation presented in IPCC [8] partly agrees with the observations presented in this study. Hansen et al. [65] has attempted to present 
simulation results from 1880 to 2003 using GISS model. Though their results concentrate mostly on change in temperature, a brief discussion on change in precipitation qualitatively agrees with the results presented here. Similarly different aspects of results presented earlier [66]-[68] agree with the observational results presented in this study.

\section{Summary and Conclusion}

An estimate of the extent of change in temperature and precipitation over the $20^{\text {th }}$ century was obtained from observation records. This was done by considering data from almost 6000 stations for temperature, and almost 10,000 stations for precipitation recorded all over the globe. Results have been obtained separately for January and July. Frequency histogram of global temperature indicates a bimodal distribution. These modes have been identified with Hadley circulation. The global temperature distribution in each of these geographical regions was observed to be negatively skewed. It has been observed that the geographical regions associated with these circulations vary between January and July. Levine \& Schneider [62] and others [63] [69] have attempted to show the dependency between Hadley circulation and climate change. Results presented here will greatly enhance the understanding of the behavior of Hadley circulation, and how it effects, and is affected by climate change.

The temperature distributions around the globe for years 1900 and 2000 were used to ascertain the change in the temperature over the century. In this respect several issues were raised which would have impact on the assessment of the change in temperature. As a result, ten different estimates were obtained for the centennial change in temperature. They were found to be within a range, though different from each other. Therefore, it is suggested that there should be a broader discussion on the methodology to estimate the change in global temperature from observational records. Nevertheless, in this study separate estimates were obtained for the change of maximum, minimum and mean temperatures. Separate estimates were obtained for January and July. The mean rise maximum and minimum temperatures for January were $1.83^{\circ} \mathrm{C}$ and $2.55^{\circ} \mathrm{C}$ respectively. The change in maximum and minimum temperatures for July was found to be $1.58^{\circ} \mathrm{C}$ and $1.86^{\circ} \mathrm{C}$ respectively. Therefore, the temperature in January has increased more than the temperature in July. Furthermore, the minimum temperature has increased more than the maximum temperature. These results greatly reduce the variability of temperature change predicted by different simulation programs, as reported by IPCC [8]. They will greatly help us to understand the dynamics of the climate. It would also greatly help in setting up simulation programs for climate change. The results here clearly point out that though the temperature has increased in most locations, globally, it also went down in almost $22 \%$ of the stations. Most of these observations qualitatively agree with simulation results reported earlier.

Change in total annual precipitation indicates that all the changes in the precipitation have taken place in the lower end of the histogram. More precipitation was recorded at stations with lower precipitation. No change has been observed in stations with very high precipitation. Although many of the observations of the change in precipitation agree with simulation, some observations are contrary to simulation. To obtain an estimate of change in precipitation, it is also felt that there should be a better agreement within the research community as to how the changes are to be evaluated.

\section{References}

[1] Good, P., Caesar, J., Bernie, D., Lowe, J.A., van der Linden, P., Gosling, S.N., Warren, R., Arnell, N.W., Smith, S., Bamber, J., Payne, T., Laxon, S., Srokosz, M., Sitch, S., Gedney, N., Harris, G., Hewitt, H., Jackson, L., Jones, C.D., O’Connor, F., Ridley, J., Vellinga, M., Halloran, P. and McNeall, D. (2011) A Review of Recent Developments in Climate Change Science. Part I: Understanding of Future Change in the Large-Scale Climate System. Progress in Physical Geography, 35, 281-296. http://dx.doi.org/10.1177/0309133311407651

[2] Gosling, S.N., Warren, R., Arnell, N.W., Good, P., Caesar, J., Bernie, D., Lowe, J.A., van der Linden, P., O’Hanley, J.R. and Smith, S.M. (2011) A Review of Recent Developments in Climate Change Science. Part II: The Global-Scale Impacts of Climate Change. Progress in Physical Geography, 35, 443-464. http://dx.doi.org/10.1177/0309133311407650

[3] van den Broeke, M.R., Bamber, J.L., Ettema, J., Rignot, E., Hurkmans, R.T.W.L., Schrama, E.J.O., van de Berg, W.J., van Meijgaard, E., Velicogna, I. and Wouters, B. (2009) Partitioning Recent Greenland Mass Loss. Science, 326, 984986. http://dx.doi.org/10.1126/science.1178176

[4] Velicogna, I. (2009) Increasing Rates of Ice Mass Loss from the Greenland and Antarctic Ice Sheets Revealed by GRACE. Geophysical Research Letters, 36, L19503. http://dx.doi.org/10.1029/2009gl040222 
[5] Stroeve, J., Holland, M.M., Meier, W., Scambos, T. and Serreze, M. (2007) Arctic Sea Ice Decline: Faster than Forecast. Geophysical Research Letters, 34, L09501. http://dx.doi.org/10.1029/2007gl029703

[6] Goosse, H., Arzel, O., Bitz, C.M., de Montety, A. and Vancoppenolle, M. (2009) Increased Variability of the Arctic Summer Ice Extent in a Warmer Climate. Geophysical Research Letters, 36, L23702. http://dx.doi.org/10.1029/2009gl040546

[7] Notz, D. (2009) The Future of Ice Sheets and Sea Ice: Between Reversible Retreat and Unstoppable Loss. Proceedings of the National Academy of Sciences USA, 106, 20590-20595. http://dx.doi.org/10.1073/pnas.0902356106

[8] IPCC (2007) Climate Change. Synthesis Report. Contribution of Working Groups I, II and III to the Fourth Assessment Report of the Intergovernmental Panel on Climate Change. IPCC, Geneva, 104 p.

[9] Rahmstorf, S. (2010) A New View On Sea Level Rise. Nature Reports, Climate Change, 4, 44-45. http://dx.doi.org/10.1038/climate.2010.29

[10] Feely, R.A., Doney, S.C. and Cooley, S.R. (2009) Ocean Acidification: Present Conditions and Future Changes in a High- $\mathrm{CO}_{2}$ World. Oceanography, 22, 36-47. http://dx.doi.org/10.5670/oceanog.2009.95

[11] Bernie, D., Lowe, J., Tyrrell, T. and Legge, O. (2010) Influence of Mitigation Policy on Ocean Acidification. Geophysical Research Letters, 37, 1-5. http://dx.doi.org/10.1029/2010GL043181

[12] Tubiello, F.N., Soussana, J.-F., Howden, S.M. and Easterling, W. (2007) Crop and Pasture Response to Climate Change. Proceedings of the National Academy of Sciences of the United States of America, 104, 19686-19690. http://dx.doi.org/10.1073/pnas.0701728104

[13] Ainsworth, E. and McGrath, J.M. (2010) Direct Effects of Rising Atmospheric Carbon Dioxide and Ozone of Crop Yields. Advances in Global Change Research, 37, 109-130. http://dx.doi.org/10.1007/978-90-481-2953-9_7

[14] Challinor, A.J. and Wheeler, T.R. (2008) Crop Yield Reduction in the Tropics under Climate Change: Processes and Uncertainties. Agricultural and Forest Meteorology, 148, 343-356. http://dx.doi.org/10.1016/j.agrformet.2007.09.015

[15] Bell, M.L., Goldberg, R., Hogrefe, C., Kinney, P.L., Knowlton, K., Lynn, B., Rosenthal, J., Rosenzweig, C. and Patz, J.A. (2007) Climate Change, Ambient Ozone, and Health in 50 US Cities. Climatic Change, 82, 61-76. http://dx.doi.org/10.1007/s10584-006-9166-7

[16] Mills, D.M. (2009) Climate Change, Extreme Weather Events, and US Health Impacts: What Can We Say? Journal of Occupational and Environmental Medicine, 51, 26-32. http://dx.doi.org/10.1097/JOM.0b013e31817d32da

[17] Washington, W.M. and Parkinson, C.L. (1986) An Introduction to Three-Dimensional Climate Modelling. University Science Books, Mill Valley.

[18] McGuffie, K. and Henderson-Sellers, A. (2001) Forty Years of Numerical Climate Modeling. International Journal of Climatology, 21, 1067-1109. http://dx.doi.org/10.1002/joc.632

[19] Peixoto, J.P. and Oort, A.H. (1992) Physics of Climate. American Institute of Physics, New York.

[20] Lockwood, J.G. (2001) Abrupt and Sudden Climatic Transitions and Fluctuatins. International Journal of Climatology, 21, 1153-1179. http://dx.doi.org/10.1002/joc.630

[21] Bony, S., Colman, R., Kattsov, V.M., Allan, R.P., Bretherton, C.S., Dufresne, J-L., Hall, A., Hallegatte, S., Holland, M.M., Ingram, W., Randall, D.A., Soden, B.J., Tselioudis, G. and Webb, M.J. (2006) How Well Do We Understand and Evaluate Climate Change Feedback Processes? Journal of Climate, 19, 3445-3482. http://dx.doi.org/10.1175/JCLI3819.1

[22] Caldeira, K., Jain, A.K. and Hoffert, M.I. (2003) Climate Sensitivity Uncertainty and the Need for Energy without $\mathrm{CO}_{2}$ Emission. Science, 299, 2052-2054. http://dx.doi.org/10.1126/science.1078938

[23] Räisänen, J. (2007) How Reliable Are Climate Models? Tellus A, 59, 2-29. http://dx.doi.org/10.1111/j.1600-0870.2006.00211.x

[24] Mitchell, J.F.B., Manabe, S., Tokioka, T. and Meleshko, V. (1990) Equilibrium Climate Change—and Its Implications for the Future. In: Houghton, J.T., Jenkins, G.J. and Ephraums, J.J., Eds., Climate Change. The IPCC Scientific Assessment, Cambridge University Press, Cambridge, United Kingdom, 131-172.

[25] Kattenberg, A., Giorgi, F., Grassl, H., Meehl, G.A., Mitchell, J.F.B., Stouffer, R.J., Tokioka, T., Weaver, A.J. and Wigley, T.M.L. (1996) Climate Models-Projections of Future Climate. In: Houghton, J.T., Meira Filho, L.G., Cllander, B.A., Harris, N., Kattenberg, A. and Maskell, K., Eds., Climate Change 1995. The Science of Climate Change, Cambridge University Press, Cambridge, 285-357.

[26] Cubasch, U., Meehl, G.A., Boer, G.J., Stouffer, R.J., Dix, M., Noda, A., Senior, C.A., Raper, S. and Yap, K.S. (2001) Projections of Future Climate Change. In: Houghton, J.T., Ding, Y., Griggs, D.J., Noguer, M., van der Linden, P.J., Dai, X., Maskell, K. and Johnson, C.A., Eds., Climate Change 2001. The Scientific Basis, Cambridge University Press, Cambridge, United Kingdom and New York, 525-582.

[27] Taylor, K.E., Stouffer, R.J. and Meehl, G.A. (2012) An Overview of CMIP5 and the Experiment Design. Bulletin of the American Meteorological Society, 93, 485-498. http://dx.doi.org/10.1175/BAMS-D-11-00094.1 
[28] Grotch, S.L. and MacCracken, M.C. (1991) The Use of General Circulation Models to Predict Regional Climate Change. Journal of Climate, 4, 286-303. http://dx.doi.org/10.1175/1520-0442(1991)004<0286:TUOGCM>2.0.CO;2

[29] Whetton, P.H., England, M.H., O’Farrell, S.P., Watterson, I.G. and Pittock, A.B. (1996) Global Comparison of the Regional Rainfall Results of Enhanced Greenhouse Coupled and Mixed Layer Ocean Experiments: Implications for Climate Change Scenario Development. Climatic Change, 33, 497-519. http://dx.doi.org/10.1007/BF00141702

[30] Kittel, T.G.F., Giorgi, F. and Meehl, G.A. (1998) Intercomparison of Regional Biases and Doubled $\mathrm{CO}_{2}$-Sensitivity of Coupled Atmosphereocean General Circulation Model Experiments. Climate Dynamics, 14, 1-15. http://dx.doi.org/10.1007/s003820050204

[31] Giorgi, F. and Francisco, R. (2000) Evaluating Uncertainties in the Prediction of Regional Climate Change. Geophysical Research Letters, 27, 1295-1298. http://dx.doi.org/10.1029/1999GL011016

[32] Räisänen, J. (2001) $\mathrm{CO}_{2}$-Induced Climate Change in CMIP2 Experiments. Quantification of Agreement and Role of Internal Variability. Journal of Climate, 14, 2088-2104. http://dx.doi.org/10.1175/1520-0442(2001)014<2088:CICCIC>2.0.CO;2

[33] Giorgi, F. and Mearns, L.O. (2002) Calculation of Average, Uncertainty Range, and Reliability of Regional Climate Changes from AOGCM Simulations via the "Reliability Ensemble Averaging” (REA) Method. Journal of Climate, 15, 1141-1158. http://dx.doi.org/10.1175/1520-0442(2002)015<1141:COAURA>2.0.CO;2

[34] Covey, C., Achuta Rao, K.M., Cubasch, U., Jones, P., Lambert, S.J., Mann, M.E., Phillips, T.J. and Taylor, K.E. (2003) An Overview of Results from the Coupled Model Intercomparison Project. Global and Planetary Change, 37, 103-133. http://dx.doi.org/10.1016/S0921-8181(02)00193-5

[35] Harvey, L.D.D. (2004) Characterizing the Annual-Mean Climatic Effect of Anthropogenic $\mathrm{CO}_{2}$ and Aerosol Emissions in Eight Coupled Atmosphere-Ocean GCMs. Climate Dynamics, 23, 569-599. http://dx.doi.org/10.1007/s00382-004-0455-4

[36] Hansen, J., Sato, M., Ruedy, R., Kharecha, P., Lacis, A., Miller, R., Nazarenko, L., Lo, K., Schmidt, G.A., Russel, G., Aleinov, I., Bauer, S., Baum, E., Cairns, B., Canuto, V., Chandler, M., Cheng, Y., Cohen, A., Del Genio, A., Faluvegi, G., Fleming, E., Friend, A., Hall, T., Jackman, C., Jonas, J., Kelley, M., Kiang, N.Y., Koch, D., Labow, G., Lerner, J., Menon, S., Novakov, T., Oinas, V., Perlwitz, J., Perlwitz, J., Rind, D., Romanou, A., Schmunk, R., Shindell, D., Stone, P., Sun, S., Streets, D., Tausnev, N., Thresher, D., Unger, N., Yao, M. and Zhang, S. (2007) Climate Simulations for 1880-2003. Climate Dynamics, 29, 61-66. http://dx.doi.org/10.1007/s00382-007-0255-8

[37] Gates, W.L., Boyle, J.S., Covey, C., Dease, C.G., Doutriaux, C.M., Drach, R.S., Fiorino, M., Gleckler, P.J., Hnilo, J.J., Marlais, S.M., Phillips, T.J., Potter, G.L., Santer, B.D., Sperber, K.R., Taylor, K.E. and Williams, D.N. (1999) An Overview of the Results of the Atmospheric Model Intercomparison Project (AMIP). Bulletin of the American Meteorological Society, 80, 29-55. http://dx.doi.org/10.1175/1520-0477(1999)080<0029:AOOTRO>2.0.CO;2

[38] Meehl, G.A., Boer, G.J., Covey, C., Latif, M. and Stouffer, J. (2000) The Coupled Model Intercomparison Project (CMIP). Bulletin of the American Meteorological Society, 81, 313-318. http://dx.doi.org/10.1175/1520-0477(2000)081<0313:TCMIPC>2.3.CO;2

[39] Fu, S., Wang, S., Xiong, Z., Gutowski, W.J., Lee, D.-K., McGregor, J.L., Sato, Y., Kato, H., Kim, J.-W. and Suh, M.-S. (2005) Regional Climate Model Intercomparison Project for Asia. Bulletin of the American Meteorological Society, 86, 257-266. http://dx.doi.org/10.1175/BAMS-86-2-257

[40] Friedlingstein, P., Cox, P., Betts, R., Bopp, L., von Bloh, W., Brovkin, V., Cadule, P., Doney, S., Eby, M., Fung, I., Bala, G., John, J., Jones, C., Joos, F., Kato, T., Kawamiya, M., Knorr, W., Lindsay, K., Mathews, H.D., Raddatz, T., Rayner, P., Reick, C., Roeckner, E., Schnitzler, K.-G., Schnur, R., Strassmann, K., Weaver, A.J., Yoshikawa, C. and Zeng, N. (2006) Climate-Carbon Cycle Feedback Analysis: Results from the C4MIP Model Intercomparison. Journal of Climate, 19, 3337-3353. http://dx.doi.org/10.1175/JCLI3800.1

[41] Hansen, J., Ruedy, R., Sato, M., Imhoff, M., Lawrence, W., Easterling, D., Peterson, T. and Karl, T. (2001) A Closer Look at United States and Global Surface Temperature Change. Journal of Geophysical Research, 106, 23947-23963. http://dx.doi.org/10.1029/2001JD000354

[42] Hansen, J., Ruedy, R., Sato, M. and Lo, K. (2010) Global Surface Temperature Change. Reviews of Geophysics, 48, 1-29. http://dx.doi.org/10.1029/2010RG000345

[43] Zweirs, F.W. and Von Storch, H. (2004) On the Role of Statistics in Climate Research. International Journal of Climatology, 24, 665-680. http://dx.doi.org/10.1002/joc.1027

[44] Reiter, A., Weidinger, R. and Mauser, W. (2012) Recent Climate Change at the Upper Danube-A Temporal and Spatial Analysis of temperature and Precipitation Time Series. Climatic Change, 111, 665-696. http://dx.doi.org/10.1007/s10584-011-0173-y

[45] Raha, A., Das, S., Banerjee, K. and Mitra, A. (2012) Climate Change Impacts on Indian Sunderbans: A Time Series Analysis (1924-2008). Biodiversity and Conservation, 21, 1289-1307. http://dx.doi.org/10.1007/s10531-012-0260-z

[46] Martínez, M.D., Serra, C., Burgueñoc, A. and Lana, X. (2010) Time Trends of Daily Maximum and Minimum Tem- 
peratures in Catalonia (ne Spain) for the Period 1975-2004. International Journal of Climatology, 30, 267-290.

[47] New, M., Todd, M., Hulme, M. and Jones, P. (2001) Precipitation Measurements and Trends in the Twentieth Century. International Journal of Climatology, 21, 1899-1922. http://dx.doi.org/10.1002/joc.680

[48] Qian, W.H. and Qin, A. (2008) Precipitation Division and Climate Shift in China from 1960 to 2000. Theoretical and Applied Climatology, 93, 1-17. http://dx.doi.org/10.1007/s00704-007-0330-4

[49] Schlüter, M.H., Merico, A., Wiltshire, K.H., Greve, W. and von Storch, H. (2008) A Statistical Analysis of Climate Variability and Ecosystem Response in the German Bight. Ocean Dynamics, 58, 169-186. http://dx.doi.org/10.1007/s10236-008-0146-5

[50] Hasselmann, K. (1993) Optimal Fingerprints for the Detection of Time Dependent Climate Change. Journal of Climate, 6, 1957-1971. http://dx.doi.org/10.1175/1520-0442(1993)006<1957:OFFTDO >2.0.CO;2

[51] Hasselmann, K. (1997) Climate-Change Research after Kyoto. Nature, 390, 225-226. http://dx.doi.org/10.1038/36719

[52] Hegerl, G.C. and North, G.R. (1997) Statistically Optimal Methods for Detecting Anthropogenic Climate Change. Journal of Climate, 10, 1125-1133. http://dx.doi.org/10.1175/1520-0442(1997)010<1125:COSOAT>2.0.CO;2

[53] Allen, M.R. and Tett, S.F.B. (1999) Checking for Model Consistency in Optimal Fingerprinting. Climate Dynamics, 15, 419-434. http://dx.doi.org/10.1007/s003820050291

[54] Hegerl, G.C. and Allen, M.R. (2002) Origins of Model-Data Discrepancies in Optimal Fingerprinting. Journal of Climate, 15, 1348-1356. http://dx.doi.org/10.1175/1520-0442(2002)015<1348:OOMDDI>2.0.CO;2

[55] Seidel, D.J. and Lanzante, J.R. (2004) An Assessment of Three Alternatives to Linear Trends for Characterizing Global Atmospheric Temperature Changes. Journal of Geophysical Research, 109, Article ID: D14108. http://dx.doi.org/10.1029/2003jd004414

[56] Hunt, B.G. and Elliot, T.I. (2006) Climatic Trends. Climate Dynamics, 26, 567-585. http://dx.doi.org/10.1007/s00382-005-0102-8

[57] Donat, M.G. and Alexander, L.V. (2012) The Shifting Probability Distribution of Global Daytime and Night-Time Temperatures. Geophysical Research Letters, 39, Article ID: L14707. http://dx.doi.org/10.1029/2012gl052459

[58] Stefanova, L., Sura, P. and Griffin, M. (2013) Quantifying the Non-Gaussianity of Wintertime Daily Maximum and Minimum Temperatures in the Southeast. Journal of Climate, 26, 838-850. http://dx.doi.org/10.1175/JCLI-D-12-00161.1

[59] Lorenz, E.N. (1967) The Nature and the Theory of the General Circulation in the Atmosphere. WMO Publication, Geneva, No. 218.

[60] Diaz, H.F. and Bradley, R.S. (2004) The Hadley Circulation: Present, Past and Future. Springer, Netherlands. http://dx.doi.org/10.1007/978-1-4020-2944-8

[61] Levine, X.J. (2013) Dynamics of Earth’s Hadley Circulation. Doctoral Dissertation, California Institute of Technology, Pasadena.

[62] Levine, X.J. and Schneider, T. (2011) Response of the Hadley Circulation to Climate Change in an Aquaplanet GCM Coupled to a Simple Representation of Ocean Heat Transport. Journal of the Atmospheric Sciences, 68, 769-783. http://dx.doi.org/10.1175/2010JAS3553.1

[63] Lui, J., Song, M., Hu, Y. and Ren, X. (2012) Changes in the Strength and Width of the Hadley Circulation. Climate of the Past, 8, 1169-1175. http://dx.doi.org/10.5194/cp-8-1169-2012

[64] Lu, J., Vecchi, G.A. and Reichler, T. (2007) Expansion of Hadley Cell under Global Warming. Geophysical Research Letters, 34, Article ID: L06805.

[65] Hansen, J., Sato, M., Ruedy, R., Lo, K., Lea, D.W. and Medina-Elizade, M. (2006), Global Temperature Change. Proceedings of the National Academy of Sciences of the United States of America, 103, 14288-14293. http://dx.doi.org/10.1073/pnas.0606291103

[66] Kharin, V.V., Zwiers, F.W., Zhang, X. and Hegerl, G.C. (2007) Changes in Temperature and Precipitation Extremes in the IPCC Ensemble of Global Coupled Model Simulations. Journal of Climate, 20, 1419-1444. http://dx.doi.org/10.1175/JCLI4066.1

[67] Trenberth, K.E., Smith, L., Qian, T., Dai, A. and Fasullo, J. (2007) Estimates of the Global Water Budget and Its Annual Cycle Using Observational and Model Data. Journal of Hydrometeorology, 8, 758-769. http://dx.doi.org/10.1175/JHM600.1

[68] Dai, A. (2007) Precipitation Characteristics in Eighteen Coupled Climate Models. Journal of Climate, 19, $4605-4630$. http://dx.doi.org/10.1175/JCLI3884.1

[69] Sun, Y., Zhou, T.J. and Zhang, L.X. (2013) Observational Analysis and Numerical Simulation of the Interannual Variability of the Boreal Winter Hadley Circulation over the Recent 30 Years. Science China: Earth Sciences, 56, 647661. http://dx.doi.org/10.1007/s11430-012-4497-x 